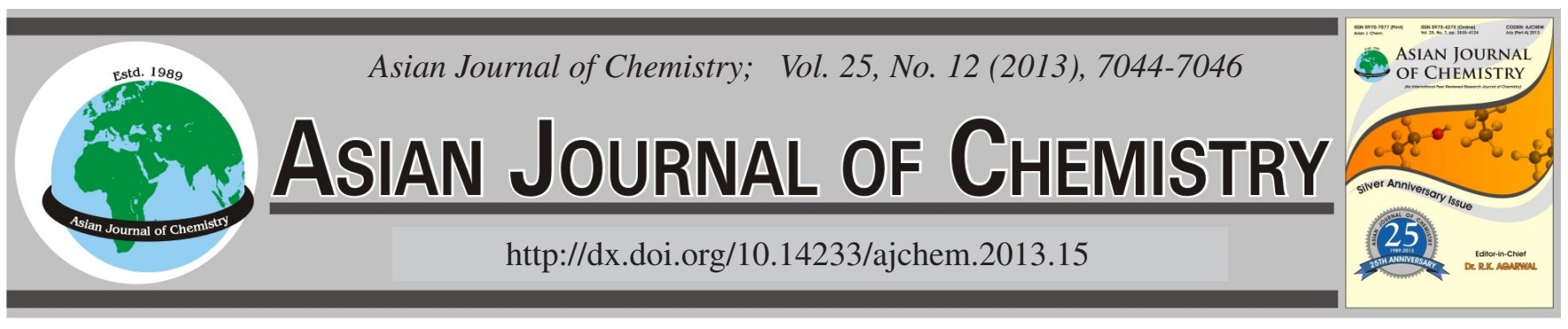

\title{
Thermal Ionization-Isotope Dilution Mass Spectrometry Determination of Ruthenium in Spent Nuclear Fuel $\dagger$
}

\author{
Young-Shin Jeon ${ }^{*}$, Yang-Soon Park, Jung-Suk Kim, Sun-Ho Han and Yong Joon Park
}

Nuclear Chemistry Research Division, Korea Atomic Energy Research Institute, 989-111 Daedeok-Daero, Yuseong-gu, Daejeon, 305-353, Republic of Korea

*Corresponding author: Fax: +82 42 8688148; E-mail: ysjeon@kaeri.re.kr

AJC-13637

\begin{abstract}
The optimum conditions for determining ruthenium in spent nuclear fuel were investigated by thermal ionization-isotope dilution mass spectrometry (TI-IDMS). Silica gel, boric acid and $\mathrm{Ba}\left(\mathrm{NO}_{3}\right)_{2}$ as an ionization enhancer and sucrose and HI solution as a reducing agent needed to be loaded with a sample on a rhenium filament. A single filament provided a large peak with increased stability and less isobaric effect than double filament. The filament current needed to be increased slowly to $5 \mathrm{~A}$ at a rate of $0.1 \mathrm{~A} / \mathrm{min}$ to obtain good results. Distillation method was effective for separation of ruthenium from the isobaric elements in a sample solution. In this optimum analytical condition, ruthenium concentration of $1,570 \mu \mathrm{g} / \mathrm{g}$ was obtained from the spent nuclear fuel (average burn-up of $57,000 \mathrm{MWd} / \mathrm{tU}$ ) sample.

Key Words: Ruthenium, Spent nuclear fuel, Determination, Thermal ionization - isotope dilution mass spectrometry.
\end{abstract}

\section{INTRODUCTION}

Ruthenium is a fission product generated when $\mathrm{UO}_{2}$ fuel burns up in a nuclear reactor ${ }^{1}$ and its isotopic ratio in a spent fuel can be used as an indicator of the irradiation behaviour of a nuclear fuel, similarly to $\mathrm{U}, \mathrm{Pu}, \mathrm{Ku}, \mathrm{Xe}, \mathrm{Cs}, \mathrm{Nd}$ and $\mathrm{Eu}$. Therefore, it is important to measure the isotopic ratio and the amount of ruthenium present in a spent fuel to assess the irradiation behaviour.

Several analytical approaches have been applied to the determination of ruthenium. When determining ruthenium spectrophotometrically ${ }^{2}$, the oxidation state of the ruthenium in a sample should be adjusted precisely during the separation process. The detection limit, $5 \mu \mathrm{g} / \mathrm{mL}$, is fairly high. Ruthenium can be determined with a detection limit of $0.005-1 \mu \mathrm{g} / \mathrm{mL}$ by atomic absorption spectrometer ${ }^{3,4}$ and inductively coupled plasma-atomic emission spectrometer ${ }^{5}$. However, these approaches are not good for highly radioactive samples because they require large amounts of sample. On the other hand, thermal ionization mass spectrometry (TIMS) is quite useful for analyzing very small amounts of highly radioactive samples. Gunji et al. ${ }^{6}$ studied thermal ionization - isotope dilution mass spectrometry (TI-IDMS) using a tungsten filament. ${ }^{96} \mathrm{Ru}$ was used as a spike to determine the ruthenium in the spent fuel and the detection limit was found to be 0.005 $\mu \mathrm{g} / \mathrm{mL}$. Huang et al. ${ }^{7}$ determined $\mathrm{RuO}_{3}{ }^{-}$by using negative thermal ionization-mass spectrometer (NTI-MS) because ruthenium has high ionization potential. Devillers et al. ${ }^{8}$ and Poths et al. ${ }^{9}$ studied the enhancement of the ionization of ruthenium using silica gel and $\mathrm{Ba}\left(\mathrm{NO}_{3}\right)_{2}$.

In this study, TI-IDMS was applied to determine ruthenium in spent fuel and the analytical conditions were optimized using rhenium filament and ${ }^{99} \mathrm{Ru}$ spike. Ionization enhancers and reducing agents were added in the sample for determining ruthenium. A single filament was used and the filament current was increased slowly to 5 A to obtain good results. Distillation method was effective for separation of $\mathrm{Ru}$ from the isobaric elements and $\mathrm{Ru}$ in spent fuel was determined in this analytical condition

\section{EXPERIMENTAL}

TIMS (Finnigan MAT 262) with a variable multi-collector with nine Faraday cups and a secondary electron multiplier (SEM) detector was used for the simultaneous determination of isotopes. The mass resolution $(\mathrm{m} / \Delta \mathrm{m})$ is $\geq 500(10 \%$ valley definition) and the abundance sensitivity for ${ }^{238} \mathrm{U}$ is $1.0 \times 10^{-6}$. A Milestone MLS-1200 MEGA microwave processor was used for the dissolution of ruthenium metal $\left({ }^{99} \mathrm{Ru}\right.$ spike).

A $1000 \mu \mathrm{g} / \mathrm{mL}$ ruthenium standard solution (Aldrich) was used for the experiment. A sucrose solution prepared by dissolving $1 \mathrm{~g}$ of sucrose (Merck) in $50 \mathrm{~mL}$ of distilled water was used as a reducing agent. $\mathrm{HI}$ and $\mathrm{Ba}\left(\mathrm{NO}_{3}\right)_{2}$ ICP-AES standard solutions were used as the reducing agent and ionization enhancer, respectively. $\mathrm{A}^{99} \mathrm{Ru}$ spike solution was prepared with

$†$ Presented to the 4th International Symposium on Applications of Chemical and Analytical Technologies in Nuclear Industries, Daejeon, Korea 
ruthenium metal (Cambridge Isotope Laboratory, USA). To prepare the ${ }^{99} \mathrm{Ru}$ spike solution, ruthenium metal $\left({ }^{99} \mathrm{Ru}\right.$ spike) was dissolved in a microwave processor. The ruthenium remaining in the vessel was filtered and heated with $500 \mathrm{mg}$ of $\mathrm{KOH}$ in a nickel crucible in a furnace for $1 \mathrm{~h}$ at $300^{\circ} \mathrm{C}, 1 \mathrm{~h}$ at $600{ }^{\circ} \mathrm{C}, 1.5 \mathrm{~h}$ at $700{ }^{\circ} \mathrm{C}$ and $0.5 \mathrm{~h}$ at $800^{\circ} \mathrm{C}$.

Separation of ruthenium from the sample solution: The distillation apparatus for the ruthenium separation is composed of a vessel in a heating mantle, a $\mathrm{RuO}_{4}$ collector containing $\mathrm{HCl}$ and $\mathrm{H}_{2} \mathrm{O}_{2}$ solution and $\mathrm{NO}_{\mathrm{x}}$ gas collector containing diluted $\mathrm{NaOH}$ solution. The apparatus was set up in a hot cell. The distillation for ruthenium separation from a sample solution was carried out for $4 \mathrm{~h}$ at $90^{\circ} \mathrm{C}$.

The following simulated spent fuel solutions were used to test the distillation performance for ruthenium separation: (1) a ruthenium solution containing isobaric elements of $\mathrm{Rh}, \mathrm{Pd}$ and Mo; (2) a solution containing the main fission products (Ru, Rh, Pd, Mo, Nd, Ce, La, Ba, Sr, Y, I, Cs and Zr); (3) a uranium solution containing the main fission products of (2).

A $0.555 \mathrm{~g}$ spent nuclear fuel sample (average burn-up of $57,000 \mathrm{MWd} / \mathrm{tU} ; 4.5 \%{ }^{235} \mathrm{U}$; cooling time of approximately 4 years) was dissolved in a 1:1 nitric acid solution. The solution was then divided equally into three containers. Nothing was added to the first solution sample, $54 \mu \mathrm{g}$ of ${ }^{99} \mathrm{Ru}$ was spiked in the second solution sample and $100 \mu \mathrm{g}$ of Ru of the ICP-AES standard solution was added as natural $\mathrm{Ru}$ to the third solution sample. Because the natural isotopic abundance of Ru includes ${ }^{99} \mathrm{Ru}$, which is not present in spent nuclear fuel, the experimental results using natural $\mathrm{Ru}$ and ${ }^{99} \mathrm{Ru}$ spikes were compared in this study.

\section{RESULTS AND DISCUSSION}

Re filament baking effect: The influence of the impurities in the unbaked rhenium filament was examined in the TIMS determination of ruthenium isotopes. The mass spectrum was recorded over the mass range $(\mathrm{m} / \mathrm{z}=84-104)$ of ruthenium isotopes after increasing the temperature of the rhenium filament without any sample; ${ }^{85} \mathrm{Rb},{ }^{87} \mathrm{Rb},{ }^{92} \mathrm{Mo},{ }^{94} \mathrm{Mo},{ }^{95} \mathrm{Mo},{ }^{96} \mathrm{Mo},{ }^{97} \mathrm{Mo}$, ${ }^{98} \mathrm{Mo}$ and ${ }^{100} \mathrm{Mo}$ were detected. $\mathrm{Rb}$ and Mo are present as impurities in the rhenium filament. ${ }^{96} \mathrm{Mo},{ }^{98} \mathrm{Mo}$ and ${ }^{100} \mathrm{Mo}$ affect the determination of ${ }^{96} \mathrm{Ru},{ }^{98} \mathrm{Ru}$ and ${ }^{100} \mathrm{Ru}$ and the production of ${ }^{85} \mathrm{Rb}^{16} \mathrm{O}^{+}(\mathrm{m} / z=101)$ by ${ }^{85} \mathrm{Rb}$ affects the determination of ${ }^{101} \mathrm{Ru}$ isotope. Therefore, a filament was baked for $50 \mathrm{~min}$ at 5.5 A to eliminate the impurities. Next, the blank test was conducted again for the baked filament and its result showed smaller peaks than the unbaked filament. However, the Mo impurity still remained in the filament in low levels; thus, a correction was required for the isobaric Mo.

Ionization enhancers and reducing agents for $\mathrm{Ru}$ mass analysis: To examine the efficiency of TIMS for Ru isotope measurements, $3 \mu \mathrm{L}$ of Ru standard solution (for ICP-AES, $1000 \mu \mathrm{g} / \mathrm{mL}$ ) was analyzed. Several small peaks were observed at the beginning. However, they disappeared at increased temperature due to the volatility of $\mathrm{RuO}_{4}$. Therefore, ionization enhancers, such as silica gel, boric acid and $\mathrm{Ba}\left(\mathrm{NO}_{3}\right)_{2}$, were loaded on a filament with Ru standard solution. However, the results were similar to the previous findings. On the other hand, when sucrose and HI solution were added to the Ru standard solution as reducing agents with ionization enhancers, the Ru isotope peaks were detected.

Stability of Ru isotope peaks according to the filament current: The single filament was more effective than the double filament for the isotopic ratio measurement of Ru by TIMS, providing a peak with sufficient intensity and a weaker isobaric effect (Fig. 1). The ${ }^{101} \mathrm{Ru}$ measurement was repeated 20 times each at filament currents of 4.5 A, 5.0 A, 5.5 A and 6.0 A. Fig. 2 showed that the ${ }^{101}$ Ru peaks were stable at a filament current $4.5 \mathrm{~A}$, but the intensity was quite low. The intensity of the peak exhibited similar trends at 5 A, 5.5 A and 6A. Therefore, the $\mathrm{Ru}$ measurement at a filament current of $5 \mathrm{~A}$ was used because the isobaric effect from the impurities contained in the filaments is lower than that for 5.5 A and 6 A. Additionally, the measurement of ${ }^{101} \mathrm{Ru}$ was repeated for filament currents slowly increasing to $5 \mathrm{~A}$ at rates of $0.1 \mathrm{~A} / \mathrm{min}, 0.2 \mathrm{~A} / \mathrm{min}$ and $0.5 \mathrm{~A} / \mathrm{min}$. Stable large peaks were obtained when the filament current was increased at a rate of $0.1 \mathrm{~A} / \mathrm{min}$ (Fig. 3).

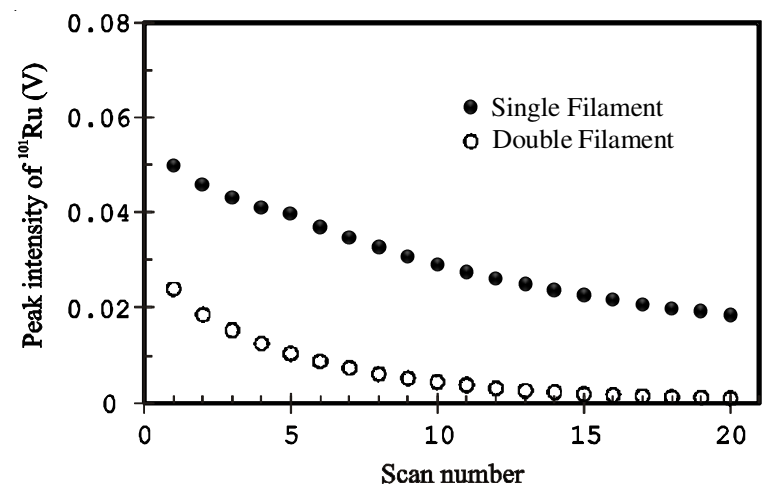

Fig. 1. ${ }^{101} \mathrm{Ru}$ peak intensity variation for repeated measurements with single and double rhenium filaments

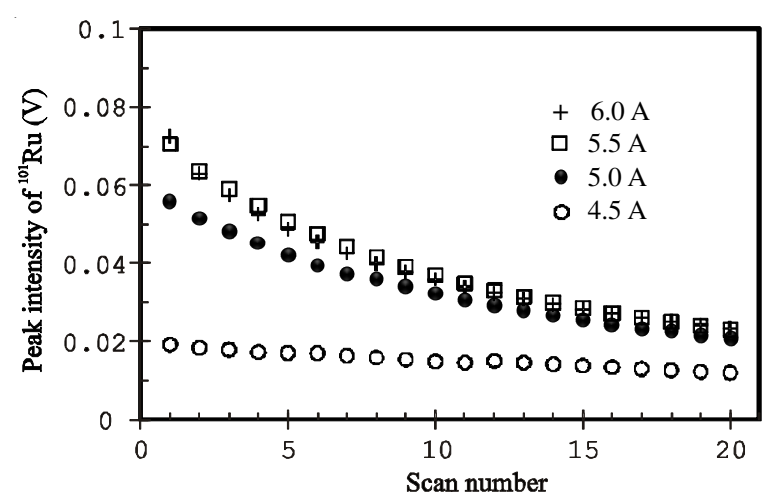

Fig. 2. ${ }^{101} \mathrm{Ru}$ peak intensity variation for repeated measurements with various rhenium filament currents

Ru separation through distillation: The solution mixed with $\mathrm{Ru}$ and its isobaric elements, such as $\mathrm{Rh}, \mathrm{Pd}$ and Mo, was distilled to identify the separation efficiency of $\mathrm{Ru}$ from the other elements. The ruthenium solution collected through the distillation of the mixed solution was analyzed using ICPAES. As shown in Table-1, only ruthenium and not any of the other elements, was detected. Consequently, ruthenium could be separated purely from the isobaric elements through distillation. To identify the recovery of ruthenium collected from spent fuel solution by distillation, ruthenium was separated from the simulated spent fuel solution and measured using 


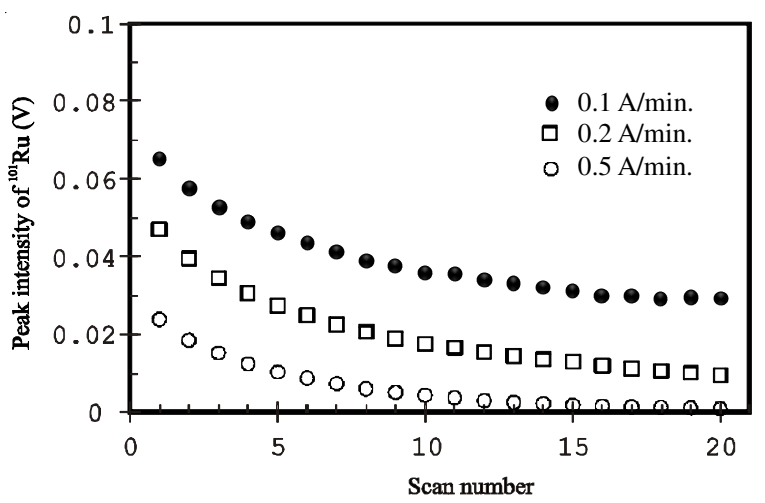

Fig. 3. ${ }^{101} \mathrm{Ru}$ peak intensity variation for repeated measurements with various rhenium filament current intervals

ICP-AES. The ruthenium recoveries were 69, 71 and $74.2 \%$ and the average value was $71.7 \%(\mathrm{RSD}, 3.1 \%)$. Although the recovery was somewhat low, the distillation was regarded as a suitable method for the separation of Ru in the spent nuclear fuel, as the ruthenium determination was not affected by the low recovery when the spike was added to the sample solution before the distillation.

TABLE-1

ICP-AES RESULTS FOR THE SOLUTION SEPARATED FROM THE SIMULATED SPENT FUEL $(\mu \mathrm{g} / \mathrm{mL})$ THROUGH DISTILLATION

\begin{tabular}{ccccc}
\hline Samples & $\mathrm{Ru}$ & $\mathrm{Rh}$ & $\mathrm{Pd}$ & $\mathrm{Mo}$ \\
\hline 1 & 3.140 & $<0.01$ & $<0.01$ & $<0.01$ \\
2 & 3.795 & $<0.01$ & $<0.01$ & $<0.01$ \\
3 & 3.163 & $<0.01$ & $<0.01$ & $<0.01$ \\
4 & 2.115 & $<0.01$ & $<0.01$ & $<0.01$ \\
5 & 2.854 & $<0.01$ & $<0.01$ & $<0.01$ \\
6 & 22.231 & $<0.01$ & $<0.01$ & $<0.01$ \\
\hline
\end{tabular}

Ru determination of a spent nuclear fuel: The amount of $\mathrm{Ru}$ in the spent nuclear fuel was analyzed using methods proven with a simulated sample solution in this study. Three dissolved solutions of the spent fuel with an average burn-up of $57 \mathrm{GWd} / \mathrm{tU}$ were prepared. ${ }^{99} \mathrm{Ru}$ spike, natural spike and no spike were added to three dissolved solutions and the ruthenium was separated by distillation. The mass spectrum for the Ru isotopes of the solution collected by distillation of the spent fuel dissolved solution (a) was obtained and compared to that of the standard solution (b) with natural Ru (Fig. 4). ${ }^{99} \mathrm{Ru}$ was detected in the standard solution but not the collected solution. Therefore, the ICP-AES standard solution with natural $\mathrm{Ru}$ could be used as a spike. The Ru isotopes were listed in Table2 after the correction of the Mo isobaric effect using the value of ${ }^{94} \mathrm{Mo} /{ }^{99} \mathrm{Ru}$. The amount of Ru in the dissolved solution of a spent fuel was analyzed by IDMS. As a result, $1570 \mu \mathrm{g} / \mathrm{g} \mathrm{Ru}$ in the samples with ${ }^{99} \mathrm{Ru}$ spike and $1574 \mu \mathrm{g} / \mathrm{g}$ Ru with natural Ru spike (ICP-AES standard solution) were determined. These values were slightly smaller than the value $(2000 \mu \mathrm{g} / \mathrm{g})$ obtained using the Origen code, likely due to low solubility of ruthenium in acidic solution.

\section{Conclusion}

The optimum conditions to determine ruthenium in a spent nuclear fuel by TI-IDMS were investigated. Silica gel, boric
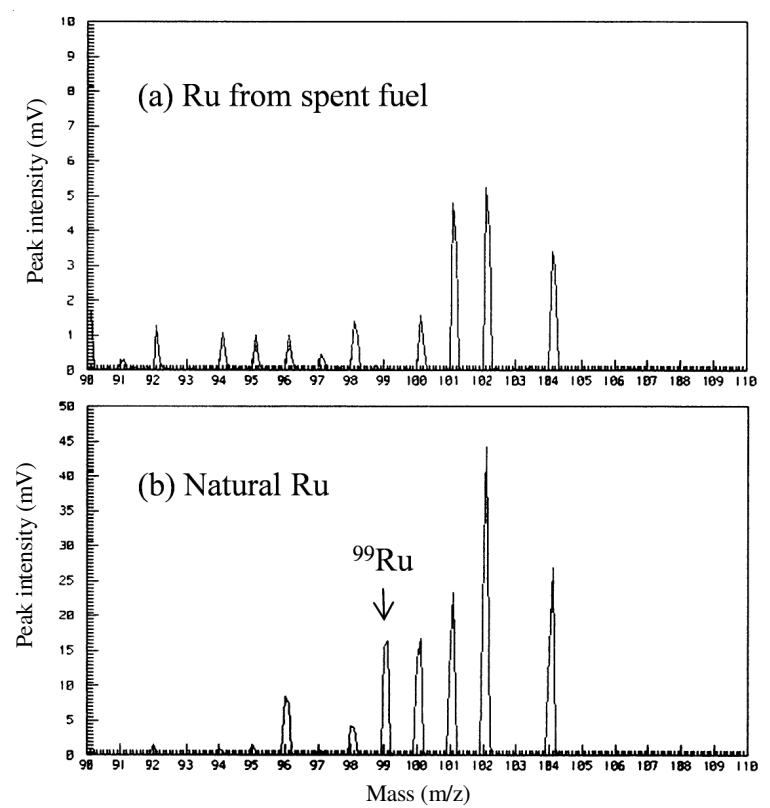

Fig. 4. Mass spectra of Ru isotopes, (a): Ru solution collected by distillation of spent fuel; (b): ICP-AES Ru standard solution

TABLE-2
RU ISOTOPES CORRECTED WITH ${ }^{94} \mathrm{Mo} /{ }^{9} \mathrm{Ru}$

acid, $\mathrm{Ba}\left(\mathrm{NO}_{3}\right)_{2}$, a sucrose and $\mathrm{HI}$ solution needed to be loaded with the sample on a rhenium filament. A single filament was used and the filament current was increased to $5 \mathrm{~A}$ at a rate of $0.1 \mathrm{~A} / \mathrm{min}$. Distillation method was effective for separation of $\mathrm{Ru}$ from the isobaric elements. The Ru concentration obtained from a spent fuel was approximately $1570 \mu \mathrm{g} / \mathrm{g}$. This value was slightly lower than the value of $2000 \mu \mathrm{g} / \mathrm{g}$ obtained using the Origen code.

\section{REFERENCES}

1. I.L. Jenkins and P.E. Brown, Radiochim. Acta, 36, 25 (1984).

2. F.E. Beamish and J.C. Van Loon, Recent Advances in the Analytical Chemistry of the Noble Metals, Pergamon Press, Oxford, p. 375 (1972).

3. M.M.M. El-Defrawy, J. Posta and M.T. Beck, Anal. Chim. Acta, 102, 185 (1978).

4. K. Motojima, K. Tatenuma, Z. Yoshida, H. Takeishi and E. Akatsu, Anal. Chim. Acta, 183, 217 (1986).

5. R.B. Wemyss and R.H. Scott, Anal. Chem., 50, 1694 (1978).

6. K. Gunji, Z. Yoshida, T. Adachi and T. Komori, J. Radioanal. Nuclear Chem., Lett., 118, 225 (1987).

7. M. Huang, Y. Liu and A. Masuda, Anal. Chem., 68, 841 (1996).

8. C. Devillers, T. Lecomte, M. Lucas and R. Hagemann, Adv. Mass Spectrom., 7A, 553 (1978).

9. H. Poths, S. Schmitt-Strecker and F. Begemann, Geochim. Cosmochim. Acta, 51, 1143 (1987). 